\title{
An Exploratory Analysis of Pronoun Usage by Brands and Consumers on Facebook
}

\author{
Ryan E. Cruz and James M. Leonhardt
}

\begin{abstract}
The importance of the language used in brand-consumer communications spans many areas of marketing including advertising, personal selling, public relations, service interactions, traditional media, and, within the last decade, digital and social media marketing. The present research provides an exploratory investigation on the use of first (e.g., "I") and second (e.g., "You") person singular pronouns in brandconsumer communications on the popular social networking platform, Facebook. In particular, archival data from brand administrator and fan posts on Facebook were collected for a period of 45 days. Initial findings suggest that first- and secondperson singular pronoun usage is higher in consumer comments than in brand posts. On the other hand, brand posts contain a higher proportion of second-person (vs. first-person) singular pronouns, while consumer comments contain a higher proportion of first-person (vs. second-person) singular pronouns. Brand posts contain a higher portion of second-person singular pronouns than do consumer comments. Finally, consumer comments contain a higher proportion of first-person singular pronouns than do brand posts. Managerial implications and opportunities for future research are discussed.
\end{abstract}

\section{References available upon request.}

R.E. Cruz $(\bowtie) \cdot$ J.M. Leonhardt

New Mexico State University, Las Cruces, NM, USA

e-mail: rycruz@nmsu.edu; jleonhar@nmsu.edu 